\title{
Health effects of the consumed water from the traditional reservoirs on the population of Tiznit in Morocco
}

\author{
Hicham Gougueni ${ }^{1,2, *}$, Latifa Ez-Zaher ${ }^{3}$, Youssef Bouchriti ${ }^{1}$, Mohamed Ait Haddou $^{1}$, and Abdelkrim Ezaidi $^{1}$ \\ ${ }^{1}$ Geoscience and Environment Team; Department of Geology; Faculty of Science; University Ibn Zohr Agadir. Morocco \\ ${ }^{2}$ Higher institute of nursing and health techniques, Agadir .Morocco \\ ${ }^{3}$ Team of Cell Biology and Molecular Genetics; Department of Biology; Faculty of Science; University Ibn Zohr Agadir. Morocco
}

\begin{abstract}
The consumption of water that does not meet the bacteriological and physico-chemical quality standards defined by national and international regulations could be the cause of various diseases and health problems The objective of this study is to study the blood balance of people consuming water stored in traditional reservoirs "matfia». The study was carried out on 30 patients hospitalized in the medical unit at Tiznit hospital coming from rural areas and who confirmed the consumption of water from "Matfia". According to the results, the patients were hospitalized for gastrology,diabetes, cardiorespiratory and dermatological problems. The study of blood tests performed for patients during their stay in the medical unit shows hemoglobin is lower than normal in $30 \%$ of women and $60 \%$ of men. For the renal check-up, uremia is above normal in $45 \%$ of cases and creatinemia in $30 \%$ of women and $50 \%$ of men. For kalemia (potassium) and natraemia (sodium) they are normal. As for the hepatic check, In $30 \%$ of cases the values of the transaminases ALAT \& ASAT are higher than the norm. Through these results, the people who consume the water of the "matfia" show the same affections and disturbances found in case of consumption of polluted water (biological and/or chemical pollution).
\end{abstract}

\section{Introduction}

Drinking water is essential for good health conditions. Drinking water must therefore be free of pathogens and/or toxic chemicals that could have health risks in the short or long-term[1]. However, water can become the source of health problems due to microbial or chemical contamination. Bacterial contamination of drinking water promotes the short-term spread of fecal-oral diseases and can cause serious illnesses such as gastroenteritis, hepatitis, typhoid, cholera and diarrhea. On the other hand, pollution of chemical origin can generate either in the medium or long term serious diseases such as irritations, allergies, abortion, cancers and chemical intoxications[2].

\section{1 water stored in traditional reservoirs}

Rainwater harvesting is a simple and low-cost technology that has been practiced for centuries. Rainwater is collected from rooftops or catchment areas and stored in different storage systems[3]. In rural and remote areas, thousands of families use rainwater tanks for drinking water [4].

To store larger quantities of water, a tank must be placed on the ground or buried. Its size can vary from one cubic metre (1,000 liters) to hundreds of cubic metres for large tanks[4]. For domestic systems at the household level, the size ranges from 10 to 30 cubic meters, and for community or school level systems it is 50 to 100 cubic meters, depending naturally on the local rainfall cycle throughout the year.

In Morocco, people in rural and remote areas use rainwater tanks called "Matfia" for water supply. These are cisterns that are located underground or above ground, where rainwater is stored to meet household, livestock and garden irrigation needs. They are widespread in many parts of Morocco. Their construction requires an investment of human effort

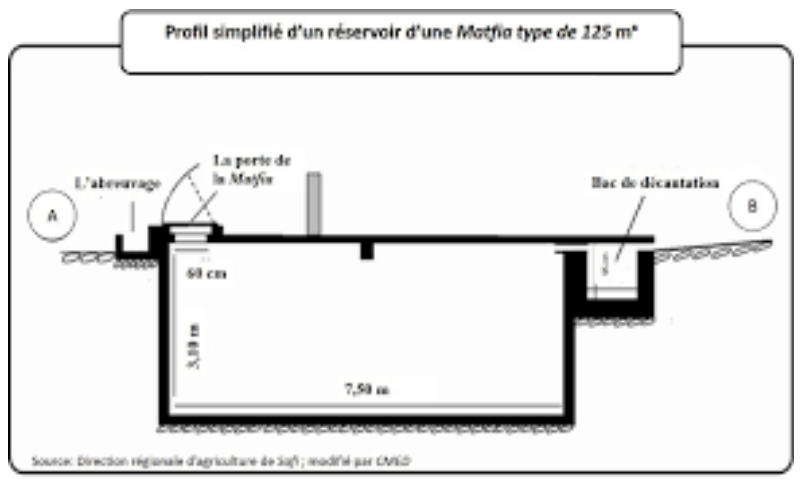

Fig. 1. Schematic drawing of a state Matfia [5].

Matfia or traditional water reservoirs are often located near the community. The collection and storage of water is done close to where people live, which makes water supplies more accessible and convenient to use.

*Corresponding author: higou79@gmail.com 


\subsection{Quality of water stored in traditional reservoirs "matfia"}

One of the major concerns of stormwater collection is the alleged concern about the quality of the water stored in the reservoir. Numerous studies on stored water pollution, conducted since 1970, have confirmed the importance of this pollution and its impact on aquatic environments[4].

\subsection{Quality of drinking water in Tiznit}

During the period from January 2018 to December 2019, a total of 414 water samples were taken by Tiznit's health and environmental technicians from five types of drinking water: water from treated networks, water from untreated networks, water from standpipes, water from untreated wells, and water from cisterns "matfia". The bacteriological analysis of these samples is carried out by the laboratory at the health and environment department in Tiznit. The results and quality of the analyzed water is assessed with reference to Moroccan quality standards; Standard (03.7.0001).

The highest non-compliances on drinking water during this period were recorded in rural areas and the category with the highest rate of non-compliance is that of untreated water (Fig. 1), mainly water from wells and cisterns "matfia". The types of germs detected in drinking water are mainly total coliforms, followed by intestinal enterococci, E. Coli and finally spores of anaerobic sulfite-reducing bacteria (Fig. 2).

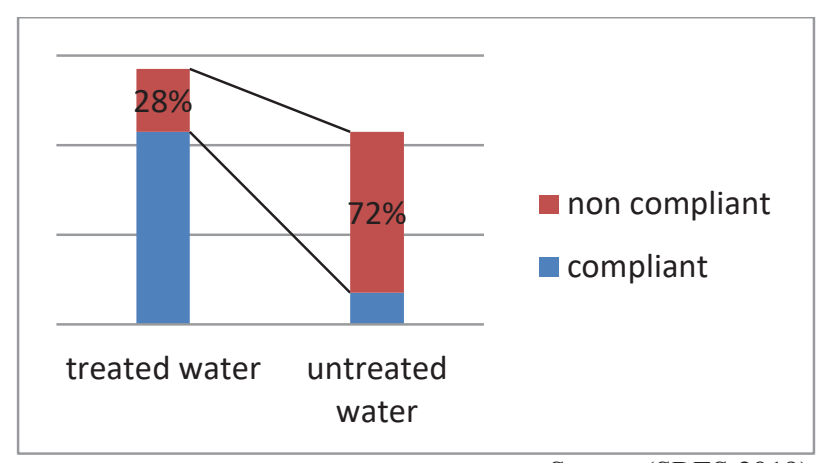

Source:(SRES,2019)

Fig. 2. Non-compliances on drinking water.

Tiznit's rural water treatment operation is based on disinfection by chlorination. According to the results of the samples taken, the chlorine concentration is almost zero. This finding is justified by the fact that disinfection control activities based on the search for free residual chlorine are carried out only in water networks and collective wells.

To analyze the microbiological quality of water, "microorganisms indicators" of fecal contamination are used, generally non-pathogenic, but indicative of the presence of pathogens from fecal matter.

The presence of Escherichia coli and intestinal enterococci is correlated with gastrointestinal disease. Escherichia coli is a bacterium present in human and animal feces.

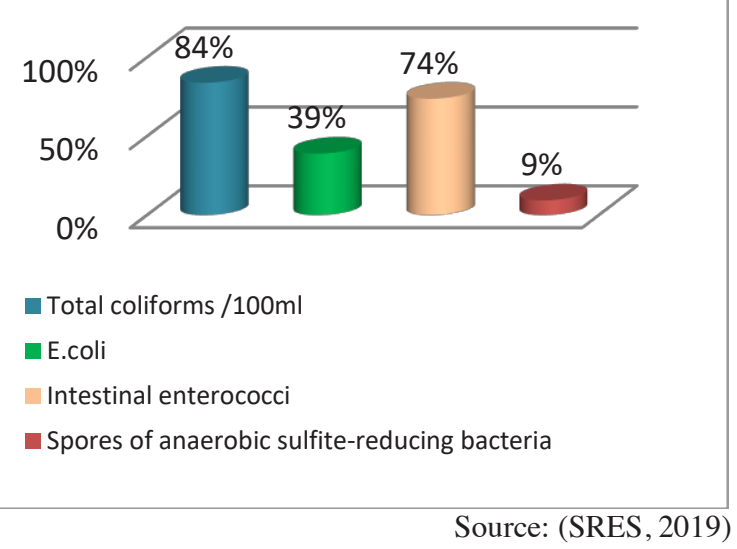

Fig. 3. Germs detected in drinking water

\section{Methods}

\subsection{Study population}

This study involved patients hospitalized in the medical unit at Tiznit hospital. Included in this study were patients who agreed to answer the questionnaire and who confirmed that they were consuming "matfia" water. Then we consult their medical records to record the results of the blood tests they had during their hospital stay.

For ethical considerations, we have obtained permission to consult the records and consents of the patients who participated in this study. Also, we were satisfied with the available tests requested by the treating doctor according to each patient's health case. Patients were not asked to perform any additional tests for this study.

\section{2 sampling method}

A total of 30 patients were accidentally selected (accidental sample). These are the patients who met the inclusion criteria and who were present at the time of our visit to the medical unit.

Several passes were required to reach a sample size of 30 patients. Only patients from rural areas where this water storage system still persists and who consume "matfia" water have been selected. Today, more than $80 \%$ of the rural population in Morocco has access to running drinking water supply, $40 \%$ of which is individually connected to the distribution network.

\subsection{Method of data collection}

Two tools were used to collect the data

\subsubsection{Questionnaire}

This instrument is used to collect information on the characteristics of the patients who participated in this study: age, sex, diagnosis and provenance. It is also used to confirm the consumption of "matfia" water through a 
closed-ended question. It contains 7 other questions related to the characteristics of "matfia":

Do you drink "matfia" water? If yes, for how long?

Where does the water stored in "Matfia" come from?

Is there a septic tank system near your matfia?

Is there any animal waste near your matfia?

Do you maintain your "Matfia"?

Do you disinfect the water of "Matfia"?

Has "matfia" water been subject to bacteriological and/or chemical quality control by the health authorities?

\subsubsection{Grid}

The grid is used to collect the data available in each patient's blood work record. The values of the renal and hepatic assessment, as well as blood glucose, hemoglobin and red blood cells are reported. The source of this data is the test reports from the hospital laboratory.

\section{Results and discussion}

Matfia water is continuously exposed to a variety of outdoor pollution sources (e.g., pathogenic microorganisms or chemical contaminants) that have the potential to spoil the quality of rainwater stored in these reservoirs [1] and [6]. Also, the storage of water leads to a deterioration of its quality because of its contamination in their reservoir. This can lead to serious public health problems, including the spread of waterborne diseases. Water-related diseases are a common problem in developing countries, mainly in rural communities that consume rainwater without appropriate microbiological quality[6].

According to the above results, the diagnoses of patients hospitalized in the medical department who consume matfia water are related to gastrointestinal (47\%), endocrinology (32\%), cardiorespiratory (27\%) and dermatological (5\%) problems (Table 1).

Table 1.Distribution of patients according to hospital diagnosis

\begin{tabular}{|c|c|c|c|}
\hline Speciality & Diagnosis & $\mathrm{Nb}$ & Total \\
\hline \multirow{7}{*}{ Gastrology } & ascites & 2 & \multirow{7}{*}{14} \\
\hline & Epigastralgia & 4 & \\
\hline & vomiting/gastric pain & 1 & \\
\hline & Constipation & 1 & \\
\hline & Abdominal bloating & 1 & \\
\hline & Acute gastroenteritis & 2 & \\
\hline & Severe anemia & 3 & \\
\hline Endocrinology & Diabetes & 8 & 8 \\
\hline \multirow{6}{*}{$\begin{array}{c}\text { Cardio/respirat } \\
\text { ory }\end{array}$} & $\begin{array}{l}\text { Lungs problem/ pleural } \\
\text { effusion }\end{array}$ & 1 & \multirow{6}{*}{7} \\
\hline & Asthma attack & 1 & \\
\hline & pneumothorax & 1 & \\
\hline & Dyspnea & 2 & \\
\hline & Heart disease & 1 & \\
\hline & Edema of lower limbs & 1 & \\
\hline Dermatology & erysipele & 1 & 1 \\
\hline
\end{tabular}

The dominance of gastrointestinal problems can be an indicator of bacteriological pollution related to the presence of microorganisms, mainly bacteria, viruses or protozoa, most of them derived from human or animal dejecta. This is confirmed by the WHO in 2017 [7] which states that the greatest health risk related to the presence of microorganisms in water results from the consumption of drinking water contaminated by human or animal excrement although other significant sources and routes of exposure have been identified.

\subsection{Hemogram}

Hemoglobin is a protein that exists inside red blood cells; it carries oxygen from the lung to other organs and tissues[8].

It corresponds to the amount of hemoglobin contained in $100 \mathrm{ml}$ of blood. It varies according to gender and normal values are (WHO, 2001):

- In men: 13 to $18 \mathrm{~g} / \mathrm{dl}$,

- In women: 12 to $16 \mathrm{~g} / \mathrm{dl}$

With regard to the blood count study, among 10 female participants, 3 had a hemoglobin value lower than normal (fig 4). Among 15male participants, 9 have a hemoglobin value below normal (fig 5).

Hemoglobin values in female participants in $\mathrm{g} / \mathrm{dl}$

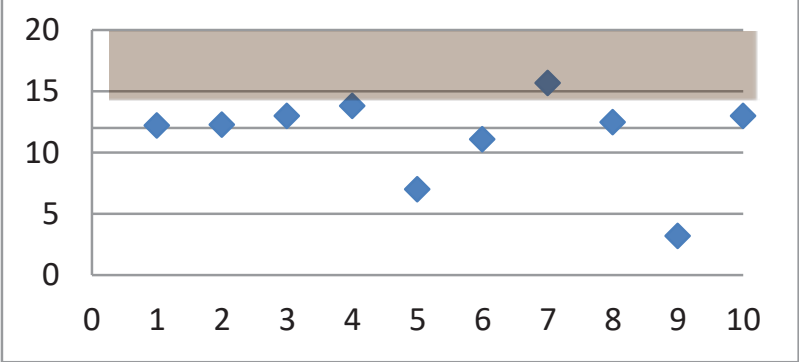

Fig. 4. Hemoglobin values in female participants in $\mathrm{g} / \mathrm{dl}$.

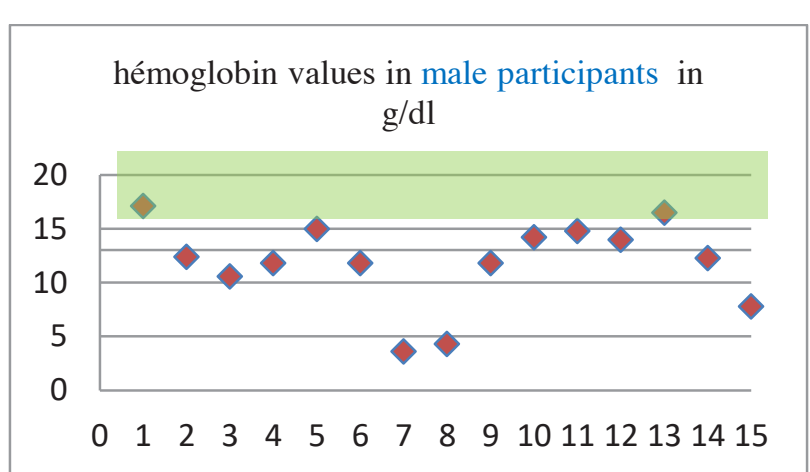

Fig. 5. Hemoglobin values in male participants in $\mathrm{g} / \mathrm{dl}$.

In enteric infections (E. coli O157:H7), diagnosis is based on a complete objective physical examination and a primary workup including a complete blood count, with particular attention to hemoglobin, hematocrit, and platelet count [9].

According to the WHO (2001), anemia corresponds to a hemoglobin level of less than $13 \mathrm{~g} / \mathrm{dl}$ in adult men and less than $12 \mathrm{~g} / \mathrm{dl}$ in adult women. Given that the causes of anemia are multiple: nutritional deficiencies, 
chronic infections, pregnancy, breastfeeding and parasitosis[8]; it is difficult to associate the presence of anemia in these patients with the consumption of Matfia water. However, this finding provides guidance towards the several parasitic etiologies that can be evoked in a subject presenting anemia [8] .

On the other hand, pollution of drinking water, particularly of chemical origin, can promote the spread of diseases including anemia [9]. Indeed, excess nitrites and nitrates can lead to severe anemia, especially in infants. Pregnant women consuming nitrate-laden water can indirectly lead to anemia in the developing child[9]. This could not be applied to this study since it involves older people (average age 63 years).

\subsection{Renal assessment}

The renal assessment consists mainly of the dosage of a few basic elements to evaluate the glomerular filtration.

\subsubsection{Creatinine}

Creatinine comes from the muscular degradation of creatine. Blood (creatinine) and urine creatinine tests are prescribed for the diagnosis of impaired renal function and for the monitoring of patients with renal insufficiency.

Normal value: Male: 80 to $110 \mu \mathrm{M} / 1$ (9 to $13 \mathrm{mg} / \mathrm{l}$ ) \& Female: 60 to $90 \mu \mathrm{M} / 1$ ( 7 to $10 \mathrm{mg} / \mathrm{l}$ )

Creatinine values exceeded the normal value in $50 \%$ of male participants (Fig 6) and 30\% of female participants (Fig 7).

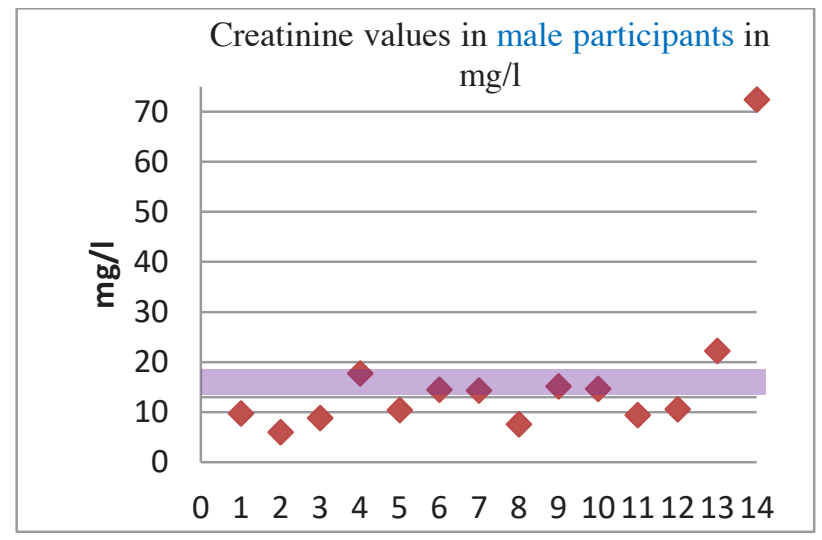

Fig. 6. Creatinine values in male participants in $\mathrm{g} / \mathrm{dl}$.

\subsubsection{Urea}

Urea is the main form of nitrogenous waste disposal from proteins and amino acids. It is synthesized in the liver during the degradation of amino acids. It is then released into the blood and excreted by the kidneys in the urine. An increase in the concentration of urea is an abnormality of kidney function. Average uremia results are between 3 and $7.5 \mathrm{mmol} / 1$ or 0.18 to $0.45 \mathrm{~g} / 1$.

According to the results of this study, abnormal urea values were found in $45 \%$ of patients (Fig 8).

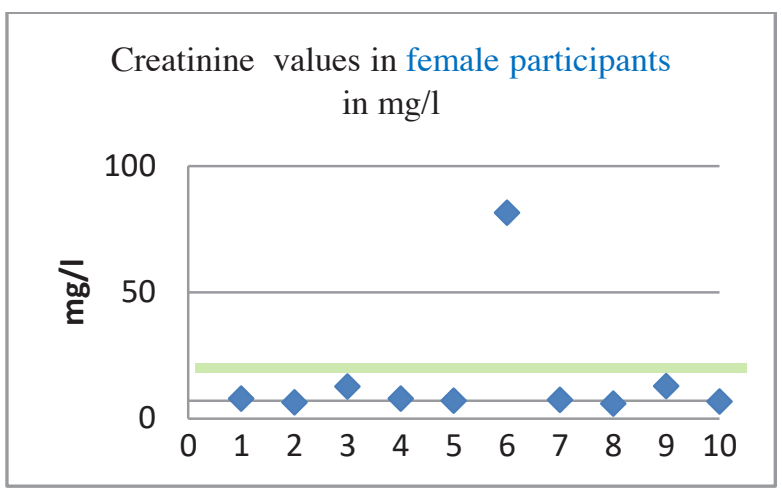

Fig. 7. creatinine values in female participants in $\mathrm{g} / \mathrm{dl}$

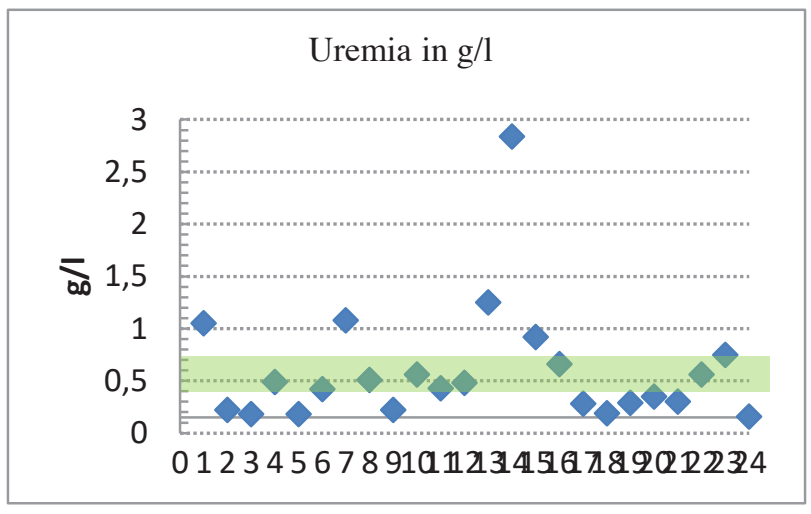

Fig. 8. Uremia values in the patients in $\mathrm{g} / \mathrm{dl}$.

Disturbances of the renal and hepatic balance in relation to drinking water are mainly related to the chemical contamination of drinking water. Exposure to lead and copper is associated with a wide range of effects, including various neurodevelopmental effects, cardiovascular disease, kidney failure and hypertension[10].

Although the probability of finding copper in matfia water is almost nil, it is important to point out that copper would be responsible, if ingested in excess of long-term permissible values, for health effects such as gastrointestinal irritation, diarrhea, nausea, abdominal pain and vomiting, as well as effects on the liver and kidneys [7]. Also, high nitrate intake induces a dosedependent increase in plasma concentrations of urea and creatinine and causes morphofunctional disorders of the kidney and could therefore be considered a causal factor of renal failure[11].

In enteric infections (E. coli O157:H7), a biochemical profile including electrolyte, urea and creatinine levels is used to assess the degree of renal impairment [9].

\subsection{Hepatic assessment}

The liver is the first organ to encounter ingested nutrients, drugs and environmental toxicants that enter the hepatic portal vein from the digestive system, and liver function can be detrimentally altered by injury resulting from acute or chronic exposure to toxicants. The results of this study show that values exceeding the 
ALAT and ASAT norms were found in only 2 participants Fig. 9.

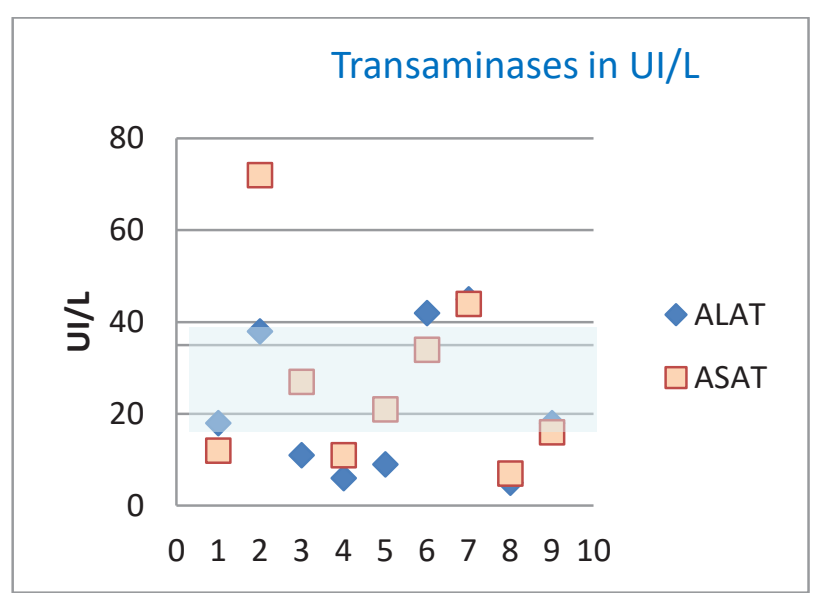

Fig. 9. Values of ALAT and ASAT in the participants in $\mathrm{g} / \mathrm{dl}$.

A study conducted by Al-Attar and al in 2011 on male mice exposed to a mixture of some heavy metals (lead, mercury, cadmium and copper) in their drinking water for seven weeks detected significant increases of blood alanine aminotransferase (ALAT), aspartate aminotransferase (ASAT), alkaline phosphatase (ALP), gamma-glutamyl-transferase (GGT) in heavy metaltreated mice [13].

\section{Conclusion}

The bacteriological and physico-chemical quality of the drinking water served to the population has been the subject of numerous studies that have shown the health risks and the impact of polluted drinking water on human health.

This study described the health problems found in a population group that consumes water stored in traditional reservoirs "matfia". Through these results, the people who consume the water from the "matfia" reservoirs show the same disorders and disturbances found in the case of consumption of polluted water (biological and/or chemical pollution). The dominance of gastrointestinal problems would be in favor of bacteriological pollution related to the presence of microorganisms, mainly bacteria, viruses or protozoa, most of them derived from human or animal dejecta. On the other hand, the pollution of drinking water, of chemical origin, can promote the spread of very serious diseases. Indeed, disturbances of the renal and hepatic balance in relation to drinking water are mainly related to the chemical contamination of drinking water.

These results are encouraging and lead us to conduct another study to evaluate the risk of Matfia water consumption in the general population. However, it remains insufficient to show the sanitary impact of the consumption of this category of water. Other studies, of correlational type, are necessary to study the chemical quality of water in relation to the health problems generated in the population.

\section{References}

1. R. P. Xavier, L. P. Siqueira, F. A. C. Vital, F. J. S. Rocha, J. I. Irmão, et G. M. T. Calazans, «Microbiological quality of drinking rainwater in the inland region of Pajeú, Pernambuco, Northeast Brazil », Rev. Inst. Med. Trop. São Paulo, vol. 53, n 3, p. 121-124, juin 2011, doi: 10.1590/S003646652011000300001.

2. P. Hartemann, «Peut-on parler d'une hiérarchie des critères de la qualité de l'eau potable? », Ann. Mines Responsab. Environ., vol. $\mathrm{N}^{\circ} 63, \mathrm{n}^{\circ} 3$, p. 55, 2011, doi: 10.3917/re.063.0055.

3. L. Fewtrell, R. B. Kaufmann, D. Kay, W. Enanoria, L. Haller, et J. M. Colford, "Water, sanitation, and hygiene interventions to reduce diarrhoea in less developed countries: a systematic review and metaanalysis », Lancet Infect. Dis., vol. 5, n ${ }^{\circ} 1$, p. 42-52, janv. 2005, doi: 10.1016/S1473-3099(04)01253-8.

4. F. Aziz, M. Farissi, J. Khalifa, N. Ouazzani, et L. Mandi, «Les réservoirs de stockage d'eau traditionnel: caractéristiques, popularité et problèmes [ Traditional storage tanks of water: characteristics, popularity and problems ] », vol. 11, no 1, p. 13, 2014.

5. E. Roose, M. Sabir, et A. Laouina, Gestion durable des eaux et des sols au Maroc: Valorisation des techniques traditionnelles méditerranéennes. IRD Éditions, 2010.

6. G. Simmons, V. Hope, G. Lewis, J. Whitmore, et W. Gao, «Contamination of potable roof-collected rainwater in Auckland, New Zealand », Water Res., vol. 35, $\mathrm{n}^{\mathrm{o}}$ 6, p. 1518-1524, avr. 2001, doi: 10.1016/S0043-1354(00)00420-6.

7. WHO. Guidelines for drinking-water 2017 ». .

8. S. Trabelsi, J. Oueslati, A. Aouinet, et S. Khaled, «EnsEignEmEnt post-univErsitairE », Tunis. Med., vol. 92, p. 7, 2014.

9. G. E Noïl, M-H. Aubé.Enteric E. coli O157:H7 infections diagnosis and treatment. the clinician . 131140 (2001)

10. K. E. Ouedghiri, A. E. Oualti, F. O. Chahdi, et A. E. O. Lalami, «Risques sanitaires liés aux composés chimiques contenus dans l'eau de boisson dans la ville de Fès : Cas des ions nitrates et nitrites (Health risks of the chemicals in drinking water in the city of Fez: nitrate and nitrite ions) », p. 9, 2014.

11. D. Debebe, F. Behulu, et Z. Getaneh, «Predicting children's blood lead levels from exposure to school drinking water in Addis Ababa, Ethiopia », J. Water Health, p. jwh2020248, mai 2020, doi: 10.2166/wh.2020.248.

12. A.Zaki, A.Ait Chaoui, A.Chait, T.Aboussaouira, K. Zarrouk, T. Himmi. Effect of ionogranic Nitrates on the morphofunctional condition of the Kidney in the rat. Thrapie;60 75-9(2005).

13. Al-Attar, A. M..Vitamin E attenuates liver injury induced by exposure to lead, mercury, cadmium and copper in albino mice. Saudi Journal of Biological Sciences, 18(4), 395-401 (2011). 